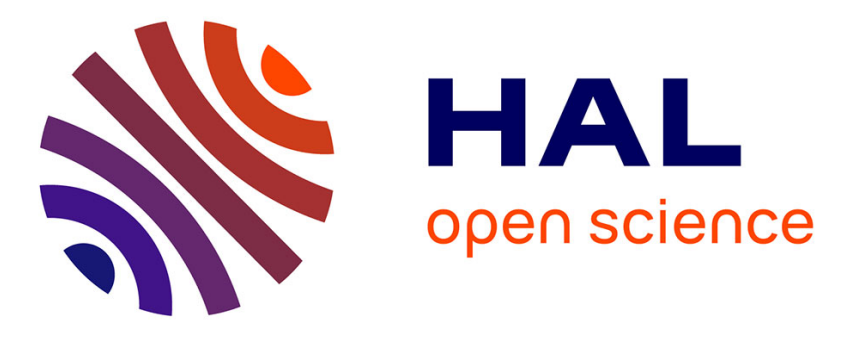

\title{
Scavenging of aerosol particles by rain in a cloud resolving model
}

S. Berthet, M. Leriche, Jean-Pierre Pinty, J. Cuesta, G. Pigeon

\section{To cite this version:}

S. Berthet, M. Leriche, Jean-Pierre Pinty, J. Cuesta, G. Pigeon. Scavenging of aerosol particles by rain in a cloud resolving model. Atmospheric Research, 2010, 96 (2-3), pp.325-336. 10.1016/j.atmosres.2009.09.015 . hal-00519461

\section{HAL Id: hal-00519461 https://hal.science/hal-00519461}

Submitted on 16 Nov 2010

HAL is a multi-disciplinary open access archive for the deposit and dissemination of scientific research documents, whether they are published or not. The documents may come from teaching and research institutions in France or abroad, or from public or private research centers.
L'archive ouverte pluridisciplinaire HAL, est destinée au dépôt et à la diffusion de documents scientifiques de niveau recherche, publiés ou non, émanant des établissements d'enseignement et de recherche français ou étrangers, des laboratoires publics ou privés. 


\title{
SCAVENGING OF AEROSOL PARTICLES BY RAIN IN A CLOUD RESOLVING MODEL
}

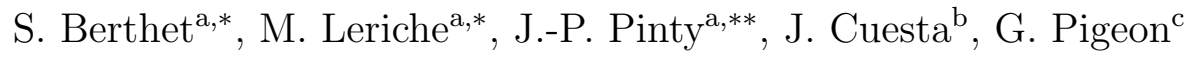 \\ ${ }^{a}$ Laboratoire d'Aérologie, University of Toulouse/CNRS, 14 avenue Edouard Belin, \\ F-31400 Toulouse, France \\ ${ }^{b}$ Laboratoire de Météorologie Dynamique, CNRS, Paris, France \\ ${ }^{c}$ Météo-France, $C N R M / 4 M$, Toulouse, France
}

\begin{abstract}
We describe a below-cloud scavenging module of aerosol particles by raindrops for use in a three-dimensional mesoscale cloud resolving model. The rate of particle removal is computed by integrating the scavenging efficiency over the aerosol particle and the drop size distributions. Here the numerical integration is performed accurately with a Gauss quadrature algorithm. The efficiency of the scavenging module is partially confirmed with experimental data. More interestingly, it is illustrated by two numerical experiments: the simulation of a forced convective circulation in a tropical cloudy boundary layer and a two-dimensional simulation of an African squall line. The results show a very selective wet removal of the aerosol particles which clearly depends on the mode radius, the width and the vertical profile of concentration. Furthermore, the squall line case shows the importance of resolving internal
\end{abstract}

\footnotetext{
*Corresponding author

${ }^{* *}$ Principal corresponding author

Email addresses: bers@aero.obs-mip.fr (S. Berthet), lerm@aero.obs-mip.fr (M. Leriche), pinjp@aero.obs-mip.fr (J.-P. Pinty), cuesta@lmd.polytechnique.fr (J. Cuesta), gregoire.pigeon@meteo.fr (G. Pigeon)
} 
circulations to redistribute layers of aerosol particles in order to improve estimates of particle removal by below-cloud scavenging.

Key words: Below Cloud Scavenging, Collision efficiency, Gauss quadratures, aerosol transport simulations

\section{Introduction}

2 Wet deposition is the most important sink of aerosol particles (AP) in 4 physical interactions between AP and hydrometeors which are categorized as 5 nucleation scavenging and impaction scavenging processes. The nucleation 6 scavenging leads to the formation of cloud droplets and ice crystals on cloud 7 condensation nuclei and on ice forming nuclei by heterogeneous nucleation, 8 respectively. The impaction scavenging applies to all the dynamical and 9 physical processes leading to the capture of AP by cloud droplets, ice crystals and mostly by falling hydrometeors. It includes Brownian diffusion, interception, inertial impaction, thermophoresis, diffusiophoresis, airflow turbulence and electrostatic attraction (Pruppacher and Klett, 1997; Andronache, 2003). The nucleation scavenging, by essence an in-cloud mechanism, dominates the impaction scavenging which is efficient once big drops are precipitating at cloud base. So the impaction scavenging is often referred to as a below-cloud scavenging (BCS) process but this does not rule out the in-cloud capture of interstitial AP by raindrops.

This study focuses on the role of BCS of AP by the raindrops thus ignoring similar effects by the snowflakes and other ice particles (see the discussion in section 4.2). We refer to the recent work of Feng (2009) for the scavenging 
of AP by snow particles of different shapes.

This work is part of a larger project, which aims at describing all the processes leading to the wet deposition of polydisperse AP in a three-dimensional (3D) cloud resolving model.

According to Pruppacher and Klett (1997), high values of BCS are found both for ultrafine particles (diameters less than $0.01 \mu \mathrm{m}$ ) and for coarse particles (diameters larger than $2 \mu \mathrm{m}$ ). Interestingly, for the intermediate range of particle size referred as the "Greenfield gap", the BCS efficiency decreases by several orders of magnitude, thus making the particles less depleted and so available for in-cloud nucleation scavenging in the upper levels.

The explicit computation of BCS rates fits well with the present capabilities of cloud resolving/mesoscale models for two reasons at least. First, these models are able to produce 3D rain fields in a consistent way (mixing ratios, and even drop concentrations depending on the microphysical scheme) and second, they resolve in detail the air flow patterns which determine the AP exposure duration of air parcels to BCS removal during rainfall events. This contrasts with estimates of BCS in global or chemistry transport models where crude approximations (see a review by Sportisse (2007)) are made about the size distribution of the raindrops or the rainfall rate estimates (Seinfeld and Pandis, 1998; Jacobson, 2003; Loosmore and Cederwall, 2004; Tost et al., 2006; Henzing et al., 2006; Feng, 2007) to cite a few. In return, considering polydisperse AP and raindrops at each gridpoint of 3D domains of simulation implies double integrations of the BCS rates over the two size distributions (Mircea et al., 2000; Andronache, 2003; Jung et al., 2003). For this reason and because of the vanishing part of the distributions, a special 
47 stressed by Sportisse (2007).

48 This study presents a flexible BCS module and illustrates some appli-

cations in the 3D mesoscale/cloud resolving model MesoNH (Lafore et al., 1998). First, the BCS module has been developed based on the widely used collision efficiency parameterization of Slinn (1983). The original module employs a quadrature method to integrate over the raindrop and the AP size distributions. Then zero-dimensional tests of the module have been done on a set of rain rates and AP concentration data from the COPS experiment (Wulfmeyer and coll., 2008), which took place in the Vosges-Black Forest area in July 2007 (see http://www.cops2007.de/). Finally, the module has been implemented and coupled to the microphysical schemes of MesoNH. Two simulations have been performed to illustrate the BCS module and its potential interactions with the transport. We studied an idealized case of a shallow tropical rainband in a $2 \mathrm{D}$ kinematic framework from the HaRP campaign (Cohard and Pinty, 2000) and a squall line case from the COPT81 experiment in West Africa (Lafore and Moncrieff, 1989). For both simulations, sensitivity tests are performed on the characteristics of the initial size distributions of AP and on the initial vertical profile of AP spectra.

\section{DEVELOPMENT OF THE BCS MODULE}

\subsection{Total number BCS rate}

A BCS module has been developed to describe the wet removal of polydisperse AP by rain precipitation inside the cloud and especially below the cloud base in the three-dimensional model MesoNH. 
$\mathrm{BCS}$ of $\mathrm{AP}$ is related to the $\mathrm{AP}$ size distribution but also to the raindrop size distribution through the BCS coefficient. Here a difficulty arises due to the complex mathematical expression of the BCS coefficient which must be integrated over wide distributions, up to infinity for analytical, log-normal or gamma laws. In order to simplify crudely the computation of a BCS rate, Tost et al. (2006) and Loosmore and Cederwall (2004) assume a monodisperse distribution of the raindrops (or equivalently an empirical "representative" raindrop diameter as shown in Fig. 4 of Sportisse (2007)) to determine the BCS coefficient $\gamma\left(d_{p}\right)$ of AP of size $d_{p}$ and the falling raindrops. A less empirical method used by Andronache (2003) and by Feng (2007) takes explicitly into account the spectral nature of the raindrop distribution by performing a numerical integration up to a large raindrop diameter. In order to keep an accurate estimate of BCS effects in MesoNH, we choose to compute BCS coefficients by means of a Gauss quadrature method (Press et al., 1992). Infinite integrals for BCS coefficients are computed as a weighted sum for a small number (here $\sim 20$ ) of optimized abscissas (each abscissa is deduced from a particle or drop diameter by a change of variable). Then, the final BCS rate of AP is obtained by integrating the BCS coefficient $\gamma\left(d_{p}\right)$ over the AP size distribution using another Gauss quadrature, adapted to the AP size distribution.

The AP are represented by the sum of several log-normal distributions $n_{p i}\left(d_{p}\right) \mathrm{d} d_{p}$ depending on the number of modes:

$$
\mathrm{d} N_{p}=\sum_{i=1}^{l} n_{p i}\left(d_{p}\right) \mathrm{d} d_{p}=\sum_{i=1}^{l} \frac{N_{p i}}{\sqrt{2 \pi} d_{p} \ln \sigma_{i}} e^{-\left(\frac{\ln \left(d_{p} / \overline{d_{p i}}\right)}{\sqrt{2} \ln \sigma_{i}}\right)^{2}} \mathrm{~d} d_{p}
$$

where $l$ is the number of modes with index $i, d_{p}$ is the AP diameter, $N_{p i}$, 
the number concentration, $\sigma_{i}$, the geometric standard deviation of the lognormal distribution, and $\overline{d_{p i}}$ is the median diameter. For the time being, we use a single-moment scheme for the AP in MesoNH (the number concentration $N_{p}$ of each mode is a prognostic variable), so $\sigma_{i}$ and $\overline{d_{p i}}$ are kept constant, depending on the AP types ${ }^{1}$. Traditionally three modes $(l=3)$ are superimposed: the Aitken nuclei mode, the accumulation mode and the coarse mode.

The raindrop size distribution $n_{R}\left(D_{d}\right)$ in MesoNH is modeled by a generalized gamma distribution $n_{R}\left(D_{d}\right)=(\alpha / \Gamma(\nu)) \lambda_{R}^{\alpha \nu} D_{d}^{\alpha \nu-1} \exp \left(-\lambda_{R} D_{d}\right)$. In this study, $n_{R}\left(D_{d}\right)$ is reduced to the classical Marshall-Palmer law by taking $\alpha=\nu=1$ for the two shape parameters:

$$
n_{R}\left(D_{d}\right) \mathrm{d} D_{d}=N_{0} e^{-\lambda_{R} D_{d}} \mathrm{~d} D_{d}
$$

where $N_{0}=8 \times 10^{-3} \mathrm{~m}^{-3} \mathrm{~mm}^{-1}, \lambda_{R}$ is the slope parameter and $D_{d}$ the drop diameter.

The method used to calculate the BCS coefficient follows the concept of the collision efficiency $E$ between an AP and a raindrop (Slinn, 1983; Pruppacher and Klett, 1997; Seinfeld and Pandis, 1998). E expresses the number of AP collected by the falling raindrop in the volume of air swept out by the raindrop. A value of $E=1$ implies that the raindrop collects all the particles encountered along the path of the fall. Most of the recent

\footnotetext{
${ }^{1}$ The residency time of falling raindrops $\left(H / V_{\text {fall }} \sim 2-5 \times 10^{2} \mathrm{~s}\right.$ where $H \sim 1000 \mathrm{~m}$ is the height of the cloud base and $V_{\text {fall }} \sim 2-5 \mathrm{~m} / \mathrm{s}$, the fallspeed of the raindrops) is short compared to the time scale of the BCS $\left(\Lambda^{-1}>10^{4} \mathrm{~s}\right.$ according to Sportisse (2007)) so, a possible modification of the median diameter $\overline{d_{p i}}$ of the AP size distribution is clearly a second-order effect compared to the variability of the rainfall rates.
} 
studies about BCS are based on this concept (Andronache, 2003; Loosmore and Cederwall, 2004; Henzing et al., 2006; Tost et al., 2006; Feng, 2007).

There is no available theoretical solution of the Navier-Stokes equation for the prediction of $E$. Therefore Slinn (1983) has formulated a semi-empirical expression of the collision efficiency $E$, taking into account three of the most understood collection processes: the Brownian diffusion, the interception and the inertial impaction. Some studies (Slinn and Hales, 1971; Wang et al., 1978; Tinsley et al., 2005) describe the relative impact of other processes such as thermo-, diffusiophoresis and electric forces upon $E$. The inclusion of these processes means to estimate the electric charge of each particle and to determine the local relative humidity along particle trajectories, complicating heavily the computation of $E$. In general these processes are ignored, as in this study. After non-dimensionalizing the equation of motion for the air, the AP and the raindrops, Slinn (1983) found an expression of $E$ that depends on five dimensionless parameters :

$$
R e=\frac{D_{d} U_{t}\left(D_{d}\right) \rho_{a}}{2 \mu_{a}}, \quad S c=\frac{\mu_{a}}{\rho_{a} \mathcal{D}}, \quad S t=\frac{2 U_{t}\left(D_{d}\right) \tau_{a}}{D_{d}}
$$

$$
\phi=\frac{d_{p}}{D_{d}}, \quad \omega=\frac{\mu_{w}}{\mu_{a}}, \quad \text { and } \quad S t^{*}=\frac{1.2+(1 / 12 \ln (1+R e))}{1+\ln (1+R e)}
$$

with symbols defined in Table 1. Seinfeld and Pandis (1998) or Sportisse (2007) provide expressions for $\mathcal{D}$ and $\tau_{a}$ which depend on $d_{p}$. In MesoNH, the terminal velocity of raindrops of diameter $D_{d}$ is approximated by a simple power law dependence in diameter that includes the air density effect expressed by Foote and Du Toit (1969):

$$
U_{t}\left(D_{d}\right)=a D_{d}^{b}\left(\frac{\rho_{a 0}}{\rho_{a}}\right)^{0.4}
$$


Finally the analytical Slinn's expression of $E$ that fits experimental data is expanded as:

$$
\begin{array}{r}
E\left(D_{d}, d_{p}\right)=\frac{4}{R e S c}[1+ \\
\left.0.4 R e^{1 / 2} S c^{1 / 3}+0.16 R e^{1 / 2} S c^{1 / 2}\right] \\
+4 \phi\left[\omega^{-1}+\left(1+2 R e^{1 / 2}\right) \phi\right] \\
+\left[\frac{S t-S t^{*}}{S t-S t^{*}+0.667}\right]^{3 / 2}\left(\frac{\rho_{p}}{\rho_{w}}\right)^{1 / 2}
\end{array}
$$

The analytical expression of the collision efficiency $E$ contains three terms corresponding to distinct physical contributions depending on the AP diameter $d_{p}$ :

1. The first term is the contribution of the Brownian diffusion. It denotes the random motion of small particles under the influence of the surrounding fluid molecules. It dominates for AP with $d_{p}<0.01 \mu m$.

2. The second term is the collection by interception. The particles follow the turbulent air motion in the wake of the drops. They are collected when their trajectory is close enough to the drop. This process affects AP with diameter between 0.01 and $2 \mu \mathrm{m}$ including AP in the "Greenfield gap".

3. The third term refers to the inertial impaction. It occurs when the particles do not follow the mean air flow because of their inertia that takes them off the streamlines. This term is efficient for large particles $\left(d_{p}>2 \mu m\right)$ with a restriction to cases where $S t>S t^{*}$ in Eq. 2 (Feng, 2007).

Wet deposition by BCS is a $1^{\text {st }}$ order decay process so that,

$$
\frac{\partial \psi\left(d_{p}, t\right)}{\partial t}=-\gamma\left(d_{p}\right) \psi\left(d_{p}, t\right)
$$


where $\psi\left(d_{p}, t\right)$ is the AP size distribution in number or mass. $\gamma\left(d_{p}\right)$ is the BCS coefficient for particles of diameter $d_{p}$. It results from the integration over the raindrop size distribution of the collision efficiency $E$ times the volume swept by a falling raindrop $D_{d}$ per unit of time,

$$
\gamma\left(d_{p}\right)=\int_{0}^{\infty} \frac{\pi}{4} D_{d}^{2} U_{t}\left(D_{d}\right) E\left(D_{d}, d_{p}\right) n_{R}\left(D_{d}\right) \mathrm{d} D_{d}
$$

(1)

A Gauss-Laguerre algorithm (Press et al., 1992), a variant of the Gauss quadrature technique, is used for the first time to integrate the above expression. The method is based on a $n$-orthogonal polynomial set associated to the weighting function, here the size distribution of the raindrops (Eq. 1). The method is a high-order optimal one which is exact when the function to integrate is smoother than a polynomial of degree $(2 n-1)$. The $\chi_{i}$ symbols denote the weights and $x_{i}$, the abscissas, then :

$$
\int_{0}^{\infty} x^{\beta} \exp (-x) f(x) \mathrm{d} x \simeq \sum_{i=1}^{n} \chi_{i} f\left(x_{i}\right) .
$$
$d_{p}$ Eq. 3:

$$
\left.\frac{\partial N_{p}}{\partial t}\right|_{B C S}=\left.\int_{0}^{\infty} \frac{\partial n_{p}\left(d_{p}\right)}{\partial t}\right|_{B C S} \mathrm{~d} d_{p}=-\int_{0}^{\infty} \gamma\left(d_{p}\right) n_{p}\left(d_{p}\right) \mathrm{d} d_{p} .
$$

This time, the integration is performed using a Gauss-Hermite quadrature formula with appropriate weights $\chi_{i}^{\prime}$ and abscissas $x_{i}^{\prime}$ :

$$
\int_{0}^{\infty} \exp \left(-x^{\prime 2}\right) f\left(x^{\prime}\right) \mathrm{d} x^{\prime} \simeq \sum_{i=1}^{n} \chi_{i}^{\prime} f\left(x_{i}^{\prime}\right) .
$$

As confirmed by a recent study (Andronache, 2003), Fig. 1 shows the BCS coefficient $\gamma\left(d_{p}\right)$ for increasing rainfall rates $R$ from 0.1 to $100 \mathrm{~mm} \cdot \mathrm{hr}^{-1}$. 
The rainfall rate $R=\int_{0}^{\infty}(\pi / 6)\left(\rho_{w} / \rho_{a}\right) D_{d}^{3} U_{t}\left(D_{d}\right) n_{R}\left(D_{d}\right) \mathrm{d}\left(D_{d}\right)$ is a function of the slope parameter $\lambda_{R}$ which defines the Marshall-Palmer distribution of the raindrops (see Eq.1). Three distinct regimes of the BCS coefficient, corresponding to those of the collision efficiency E, i.e. Brownian motion, interception and inertial impaction, can be seen in Fig. 1 with a marked "Greenfield gap" for $0.1 \mu \mathrm{m}<d_{p}<1 \mu \mathrm{m}$. The coarse AP are the most efficiently scavenged, the ultrafine particles are moderately scavenged and the scavenging is low for the intermediate mode. Moreover one can notice in Fig. 1 that the logarithm of the BCS coefficient is proportional to the logarithm of $R$, with a good approximation. These results are in agreement with those of previous studies (Andronache, 2003; Loosmore and Cederwall, 2004; Tost et al., 2006; Feng, 2007).

\subsection{Mass BCS rate}

The computation of the AP scavenging rate allows us to study the evolution of the number concentration for each AP mode $\left(N_{\text {free }}=N_{p}\right)$ and also to estimate the total mass of $\mathrm{AP}\left(m_{\text {scav }}\right)$ captured by the drops $; m_{\text {scav }}$ constitutes the depleted part of the AP in mass.

The budget equation of $m_{\text {scav }}$ is composed of three terms: a transport tendency (marked "transp"), a mass BCS removal term ("BCS") and an additional sedimentation term ("sed") because $m_{\text {scav }}$ moves at the terminal fall speed of the drops.

$$
\frac{\partial m_{\text {scav }}}{\partial t}=\left.\frac{\partial m_{\text {scav }}}{\partial t}\right|_{\text {transp }}+\left.\frac{\partial m_{\text {scav }}}{\partial t}\right|_{B C S}+\left.\frac{\partial m_{\text {scav }}}{\partial t}\right|_{\text {sed }}
$$

The mass of the free AP which are scavenged by rain, is also computed 
with the Gauss-Hermite quadrature formula, so according to Eq. 3, one gets:

$$
\left.\frac{\partial m_{\text {scav }}}{\partial t}\right|_{B C S}=-\left.\frac{\partial m_{\text {free }}}{\partial t}\right|_{B C S}=\frac{\pi}{6} \rho_{p} \int_{0}^{\infty} d_{p}{ }^{3} \gamma\left(d_{p}\right) n_{p}\left(d_{p}\right) \mathrm{d} d_{p}
$$

where both AP sphericity and constant density for each particle mode are assumed.

The mass sedimentation rate of the scavenged particles is taken proportional to the sedimentation rate of the raindrop mixing ratio $q_{R}$ :

$$
\left.\frac{1}{m_{\text {scav }}} \frac{\partial m_{\text {scav }}}{\partial t}\right|_{\text {sed }}=\left.\frac{1}{q_{R}} \frac{\partial q_{R}}{\partial t}\right|_{\text {sed }},
$$

suggesting that statistically, the mass of scavenged AP contained in an individual drop of size $D_{r}$ is proportional to the mass of the drop.

\section{QUALITATIVE APPLICATION TO THE COPS EXPERIMENT}

COPS (Convective and Orographically-induced Precipitation Study) was a 3 month international field campaign with part of a program aiming at improving precipitation forecasts (Wulfmeyer and coll., 2008). COPS took place in Summer 2007 in south-western Germany and north-eastern France. One of the goals of COPS was to collect time series of high resolution surface data including as many aerosol, cloud, and precipitation variables as possible, to be used as lower boundary conditions for mesoscale models.

Looking at the BCS process, we are interested by two types of COPS data that are both in situ measurements at $\sim 3 \mathrm{~m}$ above ground level :

- Mean rainfall rate calculated each 10 min from precipitation measurements with an Optical Rain Gauge (ORG); 
- Time evolution of AP concentrations sampled by a Grimm optical particles counter with a time step of $1 \mathrm{~min}$. The AP concentration is provided for 15 classes of particles: size cut radius $(\mu m)$ are $[0.15 ; 0.2$; $0.25 ; 0.325 ; 0.4 ; 0.5 ; 0.8 ; 1 ; 1.5 ; 2 ; 2.5 ; 3.75 ; 5 ; 7.5 ; 10 ; 20]$.

After comparing the two types of COPS data (precipitation intensity and AP concentrations), some sequences have been selected for which the aerosol depletion could be attributed to the wet removal by precipitation: the assumption is made that other processes could be neglected because of the short time duration of these sequences. Fig. 2 shows the COPS AP concentration data for Julian day 184.38 to 184.8 as well as the precipitation rate attesting the importance of scavenging for large AP.

For the moment, only the first precipitation event (between 184.38 and 184.5) is examined. During this rainfall event, the AP concentration of classes 1 to $8\left(r_{p}<1.5 \mu \mathrm{m}\right)$, is not perturbed. In contrast, the AP concentrations of large diameters (classes 9 to 11) vary and are depleted according to the rainfall event. This depletion is partly explained by BCS because, as shown in Fig. 1, the BCS rate is the highest for large diameters (classes 9 to 11) while small ones (1 to 8 ) correspond to the "Greenfield gap". Thus, the data suggest the potential effect of BCS upon the evolution of AP in the troposphere. Therefore, the implementation of this process in the aerosol continuity equation is necessary in cloud resolving models such as MesoNH.

In order to simulate the depletion of the AP by BCS using the first precipitation event from the COPS data, a mean particle diameter $\overline{d_{m}}$ has been defined for each class and the corresponding BCS coefficient $\gamma\left(\overline{d_{m}}\right)$ calculated. The method consists in initializing the AP concentrations with mea- 
sured values. Then the mean rainfall intensity data are incorporated in the BCS module for the selected rainy episode. The temporal evolution of the AP concentrations of each class of size $N_{i}$ is only driven by the calculated $\mathrm{BCS}$ rates.

For each class, the percentage of AP concentration depleted during the rainfall event, is calculated by comparing the AP concentration at the beginning and at the end of the event. This is done for measured and simulated data. As a result, the computed percentage does not reflect the entire depletion of each class of the COPS measurements. Nevertheless, the influence of the BCS effect is reproduced selectively as a function of the particle class diameter. For class number 3 (accumulation mode) and class number 10 (coarse mode) for instance (see the legend above Fig. 2), the simulated depletion percentages are $0.1 \%$ and $87 \%$ whereas the measured ones are $10.8 \%$ and $54 \%$, respectively. The discrepancy between the measured and simulated trends can be attributed to other processes such as turbulent transport, microphysics and to the assumption of homogeneous vertical profiles in the precipitating zone.

\section{2D SIMULATIONS WITH MesoNH}

The numerical experiments are performed to test and to evaluate the impact of BCS on a multimodal AP population. In all cases, particles are transported by a moist flow defined by warm or mixed-phase microphysical cycles producing rainfalls of varying characteristics along the course of the simulation. The rain mixing ratio $\left(q_{R}=\int_{0}^{\infty}(\pi / 6)\left(\rho_{w} / \rho_{a}\right) D_{d}^{3} n_{R}\left(D_{d}\right) \mathrm{d}\left(D_{d}\right)\right)$ is used to determine the raindrop size distribution $n_{R}\left(D_{d}\right)$ and to integrate 
the BCS term (Eqs. 4 and 5) in MesoNH.

\subsection{Warm shallow convection: the "HaRP" test case}

The idealized "HaRP" test case comes from "The Hawaiian Rainband Project" that took place in 1990 (Szumowski et al., 1998). It aims at simulating a precipitating cell forced by an idealized time-varying non-divergent circulation. The duration of the simulation is $50 \mathrm{~min}$. The numerical experiments are performed with the MesoNH model using a standard Kessler scheme for the microphysics and a highly accurate PPM scheme for the transport of the scalar fields. The computational domain extends over $180 \times 60$ gridpoints with a spacing of $50 \mathrm{~m}$ in the $x$ and $z$ directions. The time step is $5 \mathrm{sec}$. The concentrations of the particle modes are continuously replenished through the open lateral boundaries in the lowest $250 \mathrm{~m}$ where inflow conditions occur.

A first run is illustrated in Figs 3a-d showing the particle concentrations (grey scale), the rain mixing ratios (contours of $0.1,0.2,0.5$ and $1.0 \mathrm{~g} / \mathrm{kg}$ ) and the flow circulation with arrows. The simulation is initialized for a single log-normal distribution of AP with a median diameter of $2 \mu \mathrm{m}$. The geometric standard deviation $\sigma=2$ and the initial concentration $N=3$ $\mathrm{cm}^{-3}$ are representative of marine conditions (see mode "b" in Table 1 of Andronache (2003)). At the beginning of the simulation, the moist flow converges horizontally in the low levels initiating the formation of a cloud cell. Quickly after reaching the autoconversion threshold, the cloud droplets convert partially into raindrops which start to precipitate and to evaporate below cloud base. At the same time, the AP are entrained in the ascending motion of the flow (see the AP concentration in Fig. 3a taken after 20 min). 
After 25 min (Fig. 3b), the AP continue to rise through the rainshaft where they are partially depleted by BCS. Then the rain reaches its maximum intensity at 35 min therefore leading to an efficient depletion of AP by BCS in Fig. 3c. At the end of the simulation (so after 50 min in Fig. 3d), the AP flux diverges at the top of the cloud showing a nearly $50 \%$ reduction of the AP concentration by BCS.

In summary, the $2 \mathrm{D}$ simulation reproduces an interesting situation where $\mathrm{AP}$ are transported and accumulated by a forced convective flow in a region where raindrops are formed, precipitate and then lead to BCS. A key-aspect of our BCS treatment is that at high resolution, the BCS efficiency in a $2 \mathrm{D} / 3 \mathrm{D}$ precipitating system is thoroughly linked to the flow pattern and to the microphysical scheme. This aspect was underevaluated in most previously cited studies where observed or simulated rainfall rates are used to estimate the BCS rate of AP.

A generalization of this "HaRP" case study has been undertaken in order to explore the sensitivity of several AP size distributions to the BCS. In this series of experiment, the median diameter $\overline{d_{p}}$ varies logarithmically in the interval $10^{-3}-10^{1} \mu \mathrm{m}$ while the geometric standard deviation $\sigma$ is taken in the [1-6] range (see the compiled size distribution cases of Andronache (2003)). The results obtained for a Marshall-Palmer raindrop size distribution are plotted in Fig. 4. The figure represents the percentage of removed AP after 50 min of simulation. These scavenged AP concentrations are time and space averaged in the regions where the rain mixing ratio is larger than $0.01 \mathrm{~g} / \mathrm{kg}$. Inspection of Fig. 4, shows a continuous enhancement of the BCS with $\sigma$ for $\overline{d_{p}}<1 \mu \mathrm{m}$. This feature results from the fact that increasing the width 
of the AP log-normal distribution and holding $\overline{d_{p}}$ fixed, increases the AP size interval over which the scavenging efficiency is integrated (see Fig. 1). Consequently and because the weighting effect of the scavenging coefficient of the smallest particles dominates, the BCS increases with $\sigma$. The situation appears more complicated in the "Greenfield gap" interval $0.1-2 \mu \mathrm{m}$ of $\overline{d_{p}}$ where the BCS efficiency of AP is reduced. In this region however, the large sensitivity of the AP size distributions is fully explained by the head and the tail of the AP size distribution which involve higher and higher scavenging efficiencies as $\sigma$ increases. Moving to $\overline{d_{p}}>2$. $\mu \mathrm{m}$, i.e. to coarse AP mode, one can notice that the BCS is no more dependent on the value of $\sigma . \overline{d_{p}}$ is the leading parameter for the BCS in this AP size range. As a result, the three distinct regimes which show up in Fig. 4 are clearly correlated to the variations of the scavenging coefficients shown in Fig. 1.

A similar series of simulation performed with a Gamma $(\alpha=1, \nu=2)$ raindrop size distribution (Eq. 1) leads to a further slight enhancement of BCS (not shown here). This effect is explained simply by considering the higher concentration of big drops in the "Gamma" case compared to the Marshall-Palmer case.

The "HaRP" results show the difficulties to predict the potential scavenging of multiple AP modes without an accurate BCS module coupled to a microphysical scheme and taking into account the transport of the particles. The numerous combinations of AP log-normal distribution parameters and rain intensity clearly leads to a large variety of scavenging efficiencies. 


\subsection{Tropical squall line: the "COPT" test case}

The "COPT" test case (Caniaux et al., 1994) is typically a 12 hour simulation of a tropical squall line with kilometer scale-resolved internal circulations, a 2D turbulence scheme and mixed-phase microphysics. The model is initialized with 3 successive layers of aerosol of $2 \mathrm{~km}$ depth starting from the ground level. For each layer, the same multimodal population of particles corresponding to the "Dust Layer" case reported by Andronache (2003), is chosen for the simulation of an African squall line. The domain contains $320 \times 44$ gridpoints unevenly spaced in the vertical $(\Delta z=70 \mathrm{~m}$ at ground level and $\Delta z=700 \mathrm{~m}$ above $12 \mathrm{~km}$ ). The horizontal resolution is $1.25 \mathrm{~km}$. The model is integrated with a time step of 10 sec. A gravity wave damping layer is inserted between $17 \mathrm{~km}$ and the model top at $22.5 \mathrm{~km}$. A constant speed transformation is used to compensate for the motion of the squall line. No fluxes are considered in the surface layer. Convection is initiated by forming a $-0.01 \mathrm{~K} . \mathrm{s}^{-1}$ artificial cold pool in the low levels of a small domain during $10 \mathrm{~min}$.

Although liquid drops and frozen particles can coexist in a squall line, the study focuses on the BCS of AP by rain. In mixed-phase clouds, impaction scavenging by ice is enhanced by phoretic effects (Martin et al., 1980) and probably, by electric forces (Miller, 1990; Andronache, 2004) as these clouds become electrified by non-inductive charging mechanisms involving ice-ice shocks (Mansell, 2000; Barthe et al., 2005). This last effect clearly makes the in-cloud impaction scavenging of interstitial AP by ice difficult to describe in detail. However as the ice nucleation scavenging should dominate according to Alheit et al. (1990), the impaction scavenging of AP by ice particles is 
probably of secondary importance. As a result and because we concentrate on (tropical) warm precipitation events, in- and below-cloud scavenging effects of AP by ice and snow are not considered in this study.

The aim of this case experiment is to explore the BCS efficiency of AP layers in a long-lived mixed-phase precipitating system. In this case, we show that the residency time of air parcels (see the discussion about the merits of this aging tracer in Lucas-Picher et al. (2008)) is a useful tool to interpret the temporal aspects of the AP removal in rainy areas. Therefore, a series of simulations, without $\left(\mathrm{SCAV}_{0}\right)$ and with $\left(\mathrm{SCAV}_{1}\right)$ application of $\mathrm{BCS}$ to the dust particles, are performed. In each case, the dust particles are transported by the two-dimensional circulation that develops in the organized convective system. Figs 5a-c show the difference of dust concentrations between the twin simulations $\mathrm{SCAV}_{0}$ and $\mathrm{SCAV}_{1}$ taken after 9 hours of simulation. The plots of AP field differences allows to picture the net BCS component of the dust particle budget in a complex precipitating system.

The squall line develops in a series of narrow convective cells on the left followed by a large stratiform area with much less precipitation on the right of the figures. Here, the plotted field difference $\left(\mathrm{SCAV}_{0}-\mathrm{SCAV}_{1}\right)$ focuses on the coarse mode concentration of the dust particle distribution. The plotted fraction of the dust particles is always positive because of the reduced fraction of particle concentration when the BCS process is considered. Figs 5a-c differ only by their respective initialization: the initial dust layer was between [0-2] km for Fig. 5a, [2-4] km for Fig. 5b and [4-6] km for Fig. 5c. To summarize, the figures are showing at the same scale, the net scavenging efficiency of each initial layer of coarse dust particle mode $\left(d_{p 1}=0.55 \mu \mathrm{m}, \sigma=2.5\right)$. 
The upper glaciated part of the cloud system and the raining cells are also depicted in the figures. The initial concentration of the coarse mode is 20 $\mathrm{cm}^{-3}$ in all the simulations. A rapid inspection of Figs 5a-c indicates that all the dust layers are affected by the scavenging process which is efficient enough to eliminate much more than $1 \mathrm{~cm}^{-3}$ (scale maxima) of coarse mode particles in the heavy precipitating convective region of the squall line.

As expected the lowest dust layer (Fig. 5a) is the most affected by the scavenging removal because of stronger convergence and circulation flow intensity in the lower levels, and a longer time exposure to the precipitating area. Another interesting feature displayed in Figs 5a-c is the fate of the net scavenged particles in the upper glaciated region of the squall line, that is well above the ice freezing level at $4.5 \mathrm{~km}$ height. In Fig. 5a the relatively large difference of concentration well above the ice melting layer reflects the indirect scavenging impact in the upper glaciated region : the non-scavenged particles in simulation $\mathrm{SCAV}_{0}$ are transported upwards while they are depleted in simulation $\mathrm{SCAV}_{1}$ due to efficient BCS in the low levels. Therefore the particle concentration in the squall line upper region is clearly sensitive to BCS of low levels AP sources with potential feedback on the ice nucleation process by selectively modifying the ice nuclei spectra (for instance contact freezing nuclei which efficiency depends on particle size). The same analysis holds for Fig. 5b with a lower scavenging efficiency and less upward transport of the "mid-level" particle layer in the convectively rainy region (leftmost precipitating cells) because of a shorter residency time. In contrast, scavenging is enhanced in the trailing stratiform part of the squall line (right part of the [0-2] km layer in Figs 5a-b). This feature is explained by the presence of 
bigger raindrops (raindrops partially evaporated during their fall) which are more efficient to scavenge AP in the [2-4] km layer.

Fig. 5c shows that the BCS process still perturbs the field of AP when the dust particles are concentrated in the [4-6] km layer. Surprisingly the low-level rainy area of the squall line where convective cells develop, reveals a lot of scavenged particles even if they were not present initially in this region. The explanation is that the dust particles are recycled by the density current of the squall line (Lafore and Moncrieff, 1989). Clearly speaking, it is the internal dynamics of the squall line (convective cells, mesoscale subsidence and rear-to-front flow below the stratiform region) that transports the air and the dust of the midlevels in a downward branch, and which is responsible for the BCS depletion in the rainy area ahead. This effect is illustrated in Fig. 6 where the time evolution of a selected vertical profile (taken at $x=225$ $\mathrm{km}$ ) of the [4-6] $\mathrm{km}$ AP layer, is plotted with the rain mixing ratio. Three stages are identified in the figure. During the first 3 hours of simulation, the initial vertical distribution of AP is relatively undisturbed. Then, AP are appearing in the lower(upper) levels due to down(up)ward transport by the first convective cells of the squall line. Finally after 6 hours, the AP are continuously filling the atmosphere up to $12 \mathrm{~km}$ height. During this period of time, rainy cells are precipitating in the lowest $4.5 \mathrm{~km}$ allowing raindrops to scavenge the transported AP.

As expected, BCS is less affecting the upper glaciated region of Fig. 5c in comparison to that of Fig. 5a. The reason is that rain comes from the melting of graupel particles at $4.5 \mathrm{~km}$ altitude leading to a very shallow layer where BCS can operate locally during the ascent of the dust particles. 
In order to illustrate the importance of transport, here combined to BCS in the squall line (see also Lafore and Moncrieff (1989)), the residency time of air parcels having been in contact with rain, is shown in Fig. 5 d after 9 hours of simulation with half-hourly contours starting after 2 hours of simulation. The residency time (RT) is a 3D tracer which is easy to integrate along the course of the simulation. It includes a transport term followed by a conditional time incrementation step, here characterized by a "rain" mask. At each time step, the rainy areas are selected by considering the gridpoints passing a mask where the rain mixing ratio is larger than $0.01 \mathrm{~g} / \mathrm{kg}$ and so where RT is augmented by the value of the timestep.

Without "rain" mask (not shown here), the bulk structure of RT reproduces the mean wind shear with inflow (outflow) conditions below (above) $7.5 \mathrm{~km}$ height at the left boundary. More interestingly with the "rain" mask, there is a close resemblance between the fine scale structures of RT in Fig. 5d and the scavenged AP fields in Fig. 5a-c. For instance the wedge pattern of the scavenged AP in the low levels is reflected by a continuous increase of RT at the same place. Similarly, holes of scavenged AP at the melting level $(4.5 \mathrm{~km})$ correspond approximately to a reduced RT, meaning that fresher air parcels are less depleted by BCS. Finally, Fig. 5d reveals that a great amount of air in the glaciated part of the squall line has been exposed to the rain during 30 min at least. This demonstrates that the amount of scavenged AP depends on the rainfall rate but that it is also strongly correlated to the residency time of $\mathrm{AP}$ under the rainshaft.

The last point to examine is the mass of scavenged AP by wet deposition within the underlying surface of the COPT squall-line. Fig. 7a presents the 
surface cumulated mass of scavenged AP, assuming a density $\rho_{p}=2600$ $\mathrm{kg} \cdot \mathrm{m}^{-3}$, for the 3 layers of AP after 9 hours of simulation. The cumulated rainfall, peaking slightly downwind at $82 \mathrm{~mm} \cdot \mathrm{hr}^{-1}$, is plotted in Fig. $7 \mathrm{~b}$ for comparison. Fig. 7a shows that BCS is most pronounced for the mid layer $([2-4] \mathrm{km})$ case where it reaches $0.32 \mathrm{~kg} \cdot \mathrm{m}^{-2}$. Surprisingly, more AP are scavenged from the upper layer $([4-6] \mathrm{km})$ than from the lower layer $([0-2]$ $\mathrm{km})$. The explanation comes from the observation that the big drops which are the most efficient to scavenge AP, are present in the top layer while they are partially evaporated when they reach the bottom layer.

In summary, the COPT case offers many opportunities to investigate different aspects of AP scavenging by rain in an organized convective system where resolved flow dynamics and transport of tracers are well analysed (Lafore and Moncrieff, 1989). Here the implementation of a performant PPM transport scheme in the model is also crucial to get a deep insight into the complexity of the net BCS aspect of AP at mesoscale.

\section{CONCLUSIONS}

A BCS module has been implemented in the mesoscale/cloud resolving model MesoNH. The module is based on the collection efficiencies of Slinn (1983) with an accurate and optimized numerical integration over unbounded raindrop and AP size distributions. Then the study explores the sensitivity of BCS to various aspects of the initial AP size distribution and for two precipitating events. Here in contrast with $0 \mathrm{D} / 1 \mathrm{D}$ studies and experiments performed at larger scale, the combined effect of transport and BCS acting on AP is stressed and illustrated in the framework of $2 \mathrm{D}$ simulations. 
The HaRP numerical experiment underlines the size dependent depletion of an AP population by BCS as illustrated by changing the median diameter of log-normal distributions: the ultrafine particles are depleted, the intermediate ones remain unaltered and the large particles are scavenged dramatically. The results show also a significant sensitivity to the standard geometric deviation parameter of the AP size distributions. The simulation of the COPT squall line demonstrates the importance of coupling transport and microphysics to track the BCS effects in organized precipitating system. Here the location, with respect to the freezing level, of a layer of dust particles is a key-parameter to analyse the net effect of BCS. Some details of the depleted AP fields can be interpreted with the help of the time residency of air parcels in the rainshaft.

In conclusion, BCS of particles is expected to remove giant condensation nuclei (sea salt particles) and large ice forming nuclei (mineral dust particles) by precipitation with possible consequences on the nucleating properties of drizzling marine stratus and convective clouds with an ice phase. Therefore the next step of this work will address questions about the nucleation scavenging processes. The combination between BCS and the activation of cloud condensation nuclei is still an intriguing process in the short range evolution of the cloud cover of clean precipitating marine boundary layers (e.g. the formation of open cells in marine stratocumulus (Rosenfeld et al., 2006)).

\section{Acknowledgements}

The authors are deeply grateful to T. Maric, now at University of Washington, Seattle, WA, for the implementation of the PPM transport scheme of 


\section{References}

Alheit, R., Flossmann, A., Pruppacher, R., 1990. A theoretical study of the wet removal of atmospheric pollutants. part iv: the uptake and redistribution of aerosol particles through nucleation and impaction scavenging by growing cloud drop and ice particles. J. Atmos. Sci. 47 (7), 870-887.

Andronache, C., 2003. Estimated variability of below-cloud aerosol removal by rainfall for observed aerosol size distributions. Atmos. Chem. Phys. 3, $131-143$.

Andronache, C., 2004. Diffusion and electric charge contributions to belowcloud wet removal of atmospheric ultra-fine aerosol particles. J. Aeros. Sci. $35,1467-1482$.

Barthe, C., Molinié, G., Pinty, J.-P., 2005. Description and first results of an explicit electrical scheme in a 3D cloud resolving model. Atmospheric Research 76, 95-113.

Caniaux, G., Redelsperger, J.-L., Lafore, J.-P., 1994. A numerical study of the stratiform region of a fast-moving squall line. Part I: General description and water and heat budgets. J. Atmos. Sci. 51, 2046-2074. 
Cohard, J.-M., Pinty, J.-P., 2000. A comprehensive two-moment warm microphysical bulk scheme. II: 2D experiments with a non-hydrostatic model. Quart. J. Roy. Meteor. Soc. 126, 1843-1859.

Colella, P., Woodward, P., 1984. The piecewise parabolic method (ppm) for gas-dynamical simulations. J. Comput. Phys. 54, 174-201.

Feng, J., 2007. A 3-mode parametrization of below-cloud scavenging of aerosols for use in atmospheric dispersion models. Atmos. Environ. 41, 6808-6822.

Feng, J., 2009. A size-resolved model for below-cloud scavenging of aerosols by snowfalls. J. Geophys. Res. 114 (D08203).

Foote, G. B., Du Toit, P. S., 1969. Terminal velocity of raindrops. J. Appl. Meteor. 8, 249-253.

Henzing, J. S., Olivié, D. J. L., van Velthoven, P. F. J., 2006. A parametrization of size resolved below cloud scavenging of aerosols by rain. Atmos. Chem. Phys. 6, 3363-3375.

Jacobson, M., 2003. Development of mixed-phase clouds from multiple aerosol size distributions and the effect of the clouds on aerosol removal. J. Geophys. Res. 108 (D8), 4245.

Jung, C. H., Kim, Y. P., Lee, K. W., 2003. A moment model for simulating raindrop scavenging of aerosols. J. Aeros. Sci. 34, 1217-1233.

Lafore, J., Stein, J., Asencio, N., Bougeault, P., Ducrocq, V., Duron, J., Fischer, C., Hereil, P., Mascart, P., Pinty, V. M. J., Redelsperger, J., Richard, 
E., de Arellano, J. V.-G., 1998. The Meso-NH atmospheric simulation system. Part I: adiabatic formulation and control simulations. Annales Geophysicae 16, 90-109.

Lafore, J.-P., Moncrieff, M., 1989. A numerical investigation of the organization and interaction of the convective and stratiform regions of tropical squall lines. J. Atmos. Sci. 46, 531-544.

Loosmore, G. A., Cederwall, R. T., 2004. Precipitation scavenging of atmospheric aerosols for emergency response applications: testing an updated model with new real-time data. Atmos. Environ. 38, 993-1003.

Lucas-Picher, P., Caya, D., Biner, S., Laprise, R., 2008. Quantification of the lateral boundary forcing of a regional climate model using an aging tracer. Mon. Wea. Rev. 136 (12), 49804996.

Mansell, E. R., 2000. Electrification and lightning in simulated supercell and non-supercell thunderstorms. Ph.D. thesis, Univ. Oklahoma.

Martin, J., Wang, P., Pruppacher, H., 1980. A theoretical determination of the efficiency with which aerosol particles are collected by simple ice crystal plates. J. Atmos. Sci. 37, 1628-1638.

Miller, N., 1990. A model for the determination of the scavenging rates of submicron aerosols by snow crystals. Atmospheric Research 25, 317-330.

Mircea, M., Stefan, S., Fuzzi, S., 2000. Precipitation scavenging coefficient: influence of measured aerosol and raindrop size distributions. Atmospheric Research 34, 5169-5174. 
Press, W. H., Teukolsky, S. A., Vetterling, W. T., Flannery, B. P., 1992. Numerical Recipes in FORTRAN: The Art of Scientific Computing. Cambridge University Press.

Pruppacher, H., Klett, J., 1997. Microphysics of Clouds and Precipitation. Kluwer Academic Publishers, Dordrecht, The Netherlands.

Rosenfeld, D., Kaufman, Y. J., Koren, I., 2006. Switching cloud cover and dynamical regimes from open to closed Benard cells in response to the suppression of precipitation by aerosols. acp 6, 2503-2511.

Seinfeld, J. H., Pandis, S. N., 1998. Atmospheric Chemistry and Physics. Wiley, New York.

Slinn, W., 1983. Precipitation scavenging, in Atmospheric Sciences and Power Production 1979 (Chap.11). Division of Biomedical Environment Research, U.S. Department of Energy, Washington, D.C.

Slinn, W., Hales, J. M., 1971. A reevaluation of the role of thermophoresis as a mechanism of in- and below-cloud scavenging. J. Atmos. Sci. 28 (8), $1465-1471$.

Sportisse, B., 2007. A review of parameterizations for modelling dry deposition and scavenging of radionuclides. Atmos. Environ. 41, 2683-2698.

Szumowski, M., Grabowski, W., Ochs, H., 1998. Simple two-dimensional kinematic framework designed to test warm rain microphysical models. Atmospheric Research 45, 299-326. 
Tinsley, B. A., Zhou, L., Plemmons, A., 2005. Changes in scavenging of particles by droplets due to weak electrification in clouds. Atmospheric Research 79, 266-295.

Tost, H., Joeckel, P., Kerkweg, A., Sander, R., Lelieveld, J., 2006. Technical note: A new comprehensive SCAVenging submodel for global atmospheric chemistry modelling. Atmos. Chem. Phys. 6, 565-574.

Wang, P. K., Grover, S. N., Pruppacher, H. R., 1978. On the effect of electric charges on the scavenging of aerosol particles by clouds and small raindrops. J. Atmos. Sci. 35, 1735-1743.

Wulfmeyer, V., coll., 2008. The convective and orographically-induced precipitation study: A research and development project of the world weather research program for improving quantitative precipitation forecasting in low-mountain regions. Bull. Am. Meteorol. Soc. 89 (10), 1477-1486, DOI:10.1175/2008BAMS2367.1. 


\begin{tabular}{|c|c|c|c|}
\hline$\left\{\begin{array}{l}a=842 \\
b=0.8\end{array}\right.$ & Parameters of $U_{t}\left(D_{d}\right)$ & $N_{p i}$ & Number concentration of AP mode $\mathrm{i}$ \\
\hline$d_{p}$ & AP diameter & $n_{p i}\left(d_{p}\right)$ & AP size distribution of mode i \\
\hline$\overline{d_{p i}}$ & Median diameter of mode i & $n_{R}\left(D_{d}\right)$ & Raindrop size distribution \\
\hline$D_{d}$ & Drop diameter & $q_{R}$ & Rain mixing ratio \\
\hline $\mathcal{D}$ & AP diffusivity & $R$ & Rainfall rate \\
\hline$E\left(D_{d}, d_{p}\right)$ & AP-droplets collision efficiency & $R e$ & Raindrop Reynolds number \\
\hline$f\left(x_{i}\right)$ & Function to integrate & $r_{p}$ & AP radius \\
\hline$i, l$ & Index of AP mode & $S c$ & AP Schmidt number \\
\hline$m_{\text {free }}$ & Mass of free AP & $S t$ & AP Stokes number \\
\hline$m_{\text {scav }}$ & Total mass of scavenged AP & $S t *$ & Critical Stokes number \\
\hline$n$ & Order of the Gauss quadrature & $U_{t}\left(D_{d}\right)$ & Terminal fall velocity of raindrops \\
\hline$N_{0}$ & Marshall-Palmer parameter & $x_{i}, x_{i}^{\prime}$ & Abcissa for Gauss quadrature \\
\hline$N_{\text {free }}$ & Number concentration of free AP & & \\
\hline$\alpha$ & Parameters of $n_{R}\left(D_{d}\right)$ & $\Psi\left(d_{p}, t\right)$ & Mass or number AP size distribution \\
\hline$\beta$ & Parameter of the Gamma function & $\rho_{a 0}$ & Reference air density at ground level \\
\hline$\gamma\left(d_{p}\right)$ & BCS coefficient & $\rho_{a}$ & Reference density of dry air \\
\hline$\Gamma$ & Gamma function & $\rho_{p}$ & AP density \\
\hline$\lambda_{R}$ & Marshall-Palmer slope parameter & $\sigma_{i}$ & Standard deviation of mode i \\
\hline$\mu_{a}$ & Dynamic viscosity of dry air & $\tau_{a}$ & Relaxation time of the collected AP \\
\hline$\mu_{w}$ & Water viscosity & $\chi_{i}, \chi_{i}^{\prime}$ & Weights for Gauss quadrature \\
\hline$\nu$ & Parameters of $n_{R}\left(D_{d}\right)$ & $\omega$ & Viscosity ratio \\
\hline$\phi$ & Ratio of diameters & & \\
\hline
\end{tabular}

Table 1: Definition and unit of symbols used in this article. 


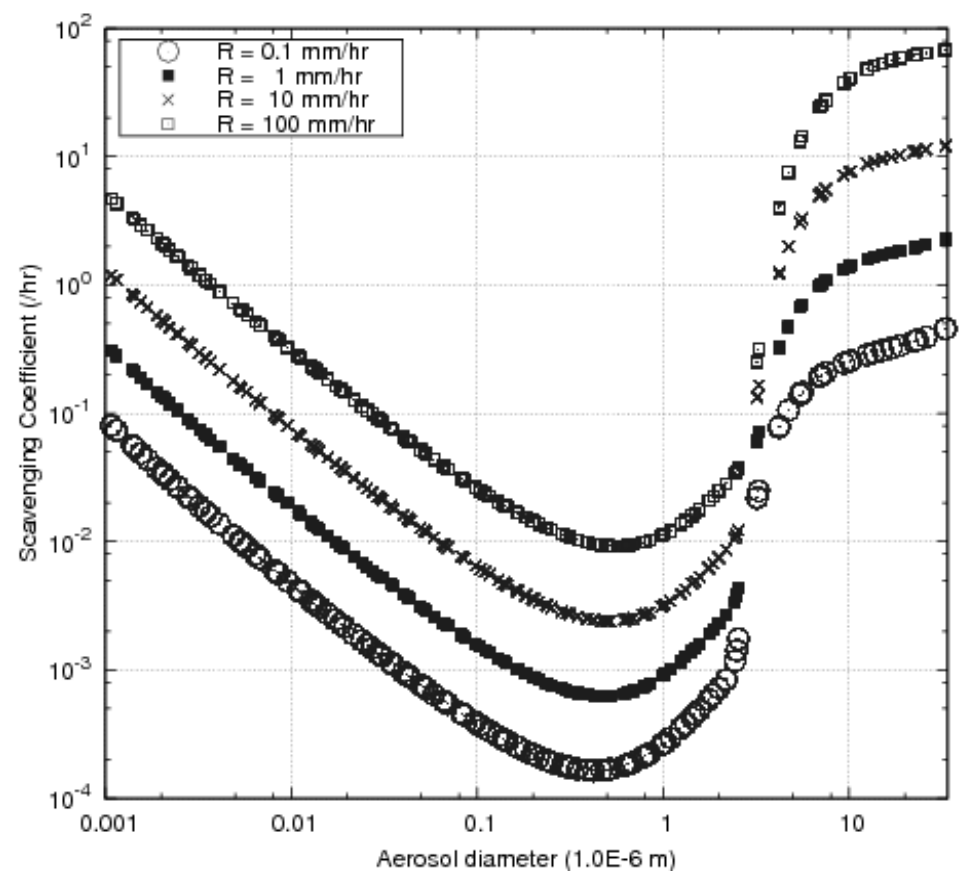

Figure 1: Scavenging coefficient as a function of particle size and rain rate (calculated with Eq.(4)) 


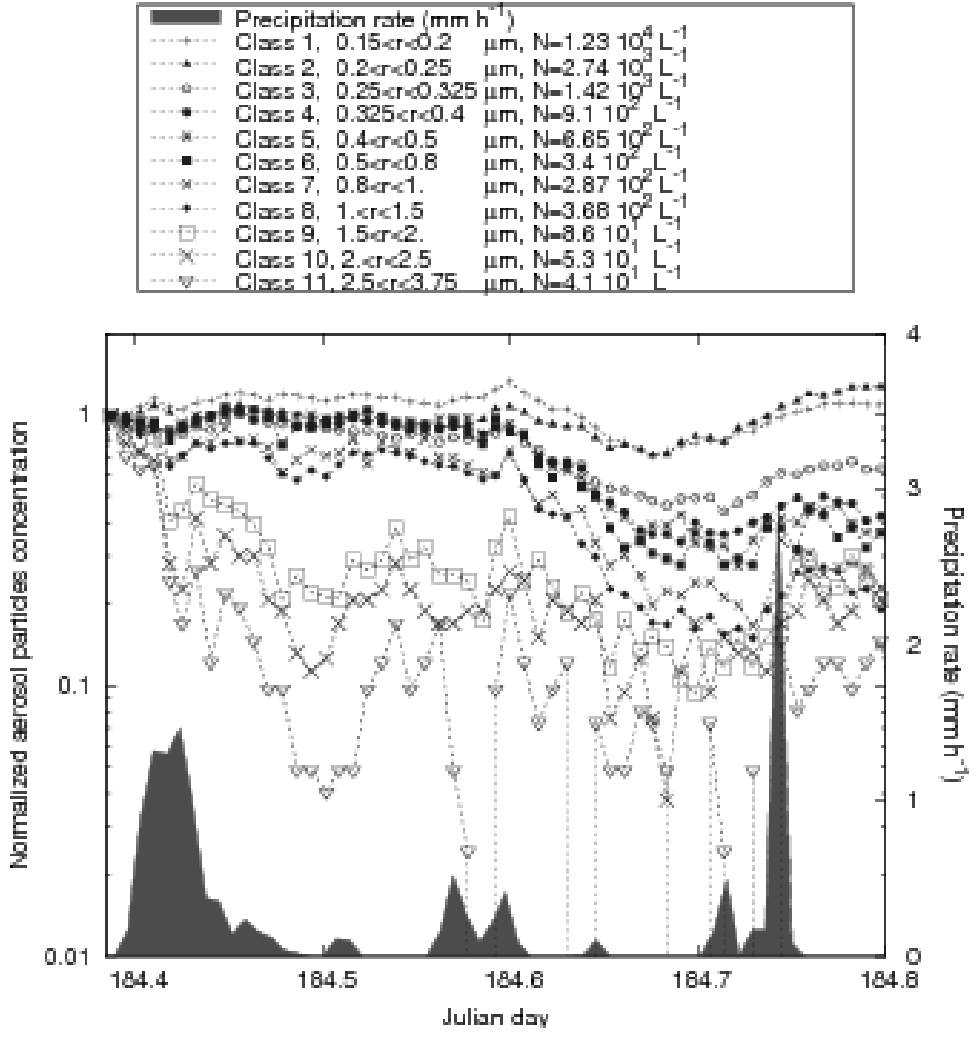

Figure 2: A short sequence of aerosol data and rainfall rate observed during COPS experiment 
a)

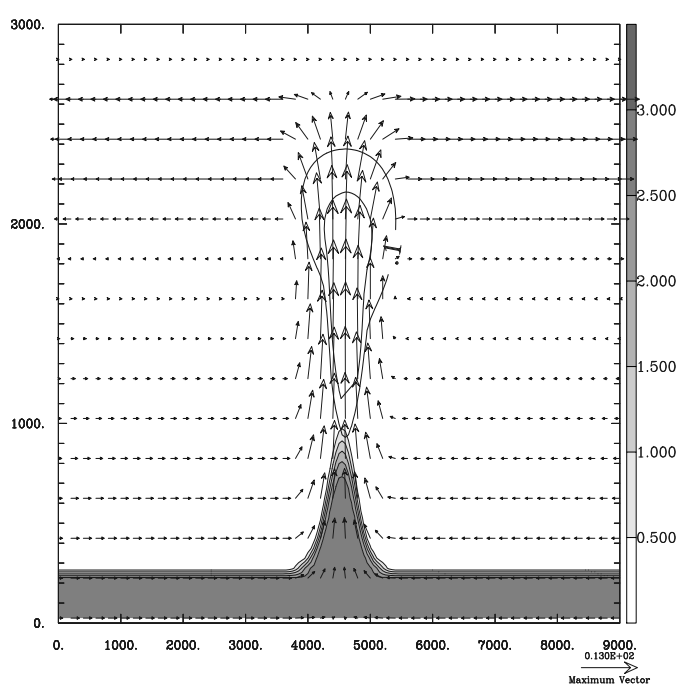

c)

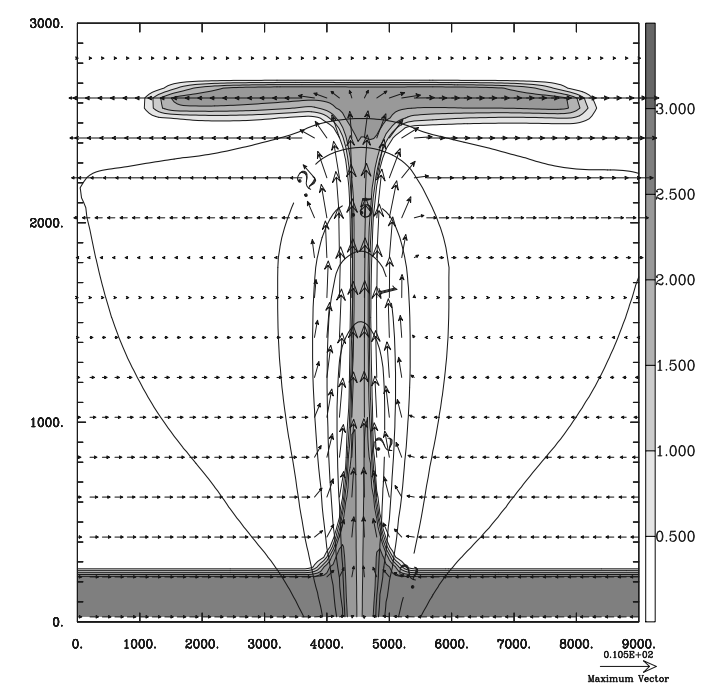

b)

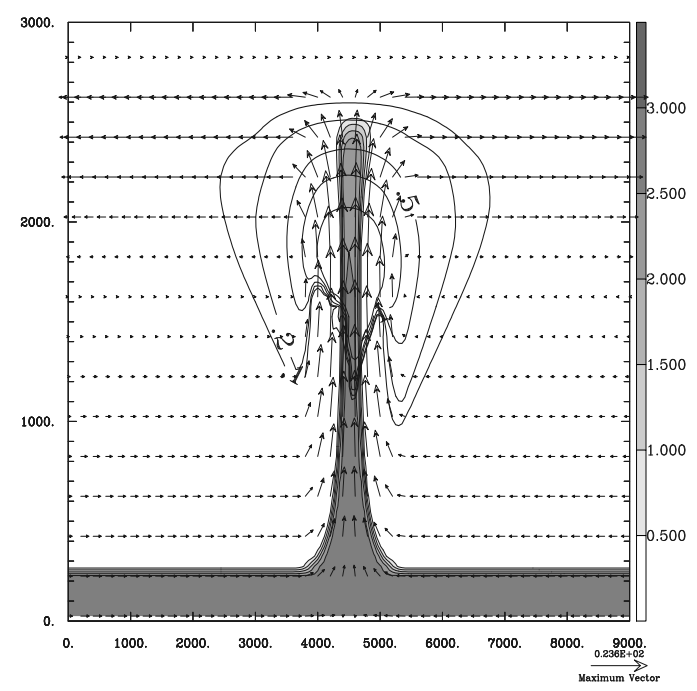

d)

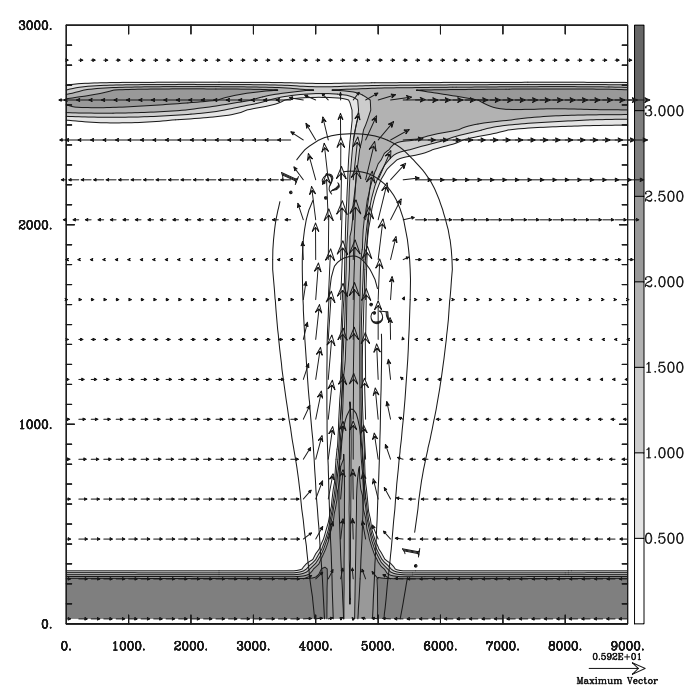

Figure 3: Concentration $\left[\mathrm{cm}^{-3}\right]$ of a log-normal particle mode with $N=3 \mathrm{~cm}^{-3}, \overline{d_{p}}=2$ $\mu \mathrm{m}$ and $\sigma=2$ after a) $20 \mathrm{~min}$, b) $25 \mathrm{~min}$, c) $35 \mathrm{~min}$ and d) $50 \mathrm{~min}$ of simulation of the "HaRP" case. Rain mixing ratio contours (for 0.1, 0.2, 0.5 and $1.0 \mathrm{~g} / \mathrm{kg}$ ) and flow structure (arrows) are superimposed. 


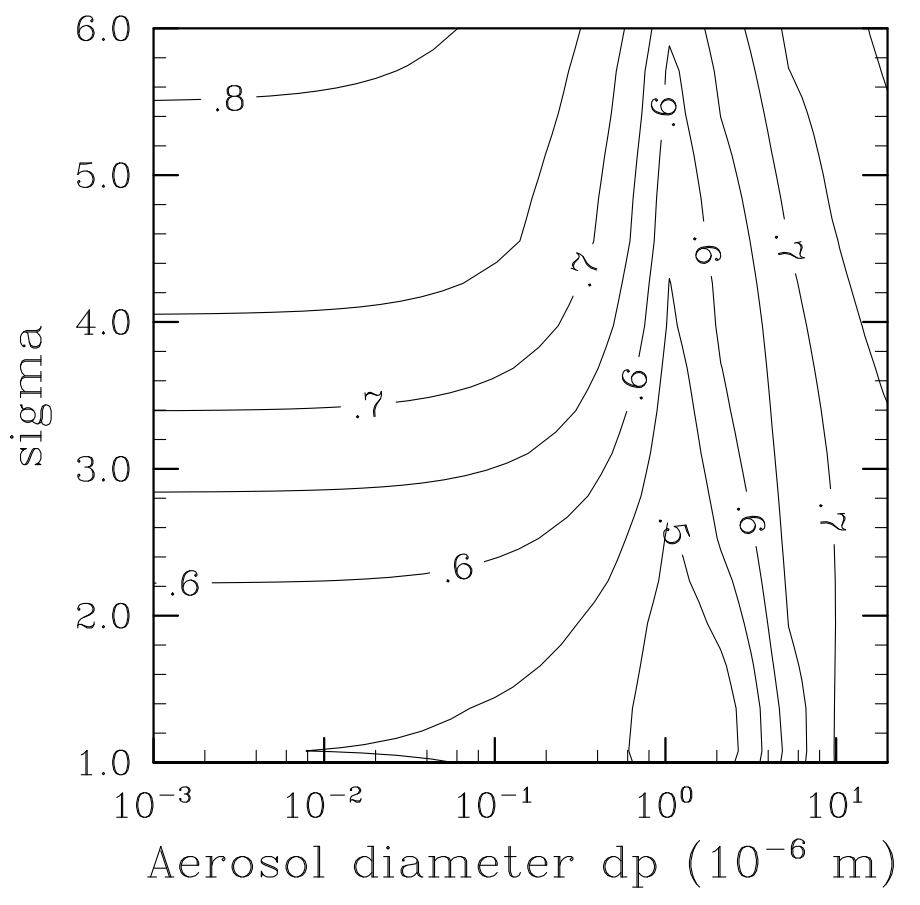

Figure 4: Fraction of scavenged AP as a function of the median diameter $\overline{d_{p}}$ and of the geometric standard deviation $\sigma$ of the AP log-normal size distribution. The results obtained for a Marshall-Palmer distribution of the raindrops after 50 min of simulation of the "HaRP" case. 
a)

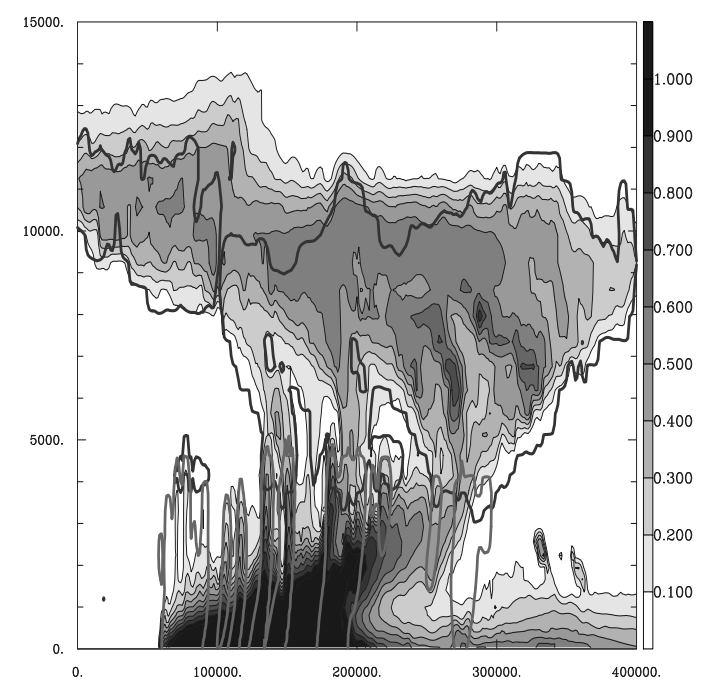

c)

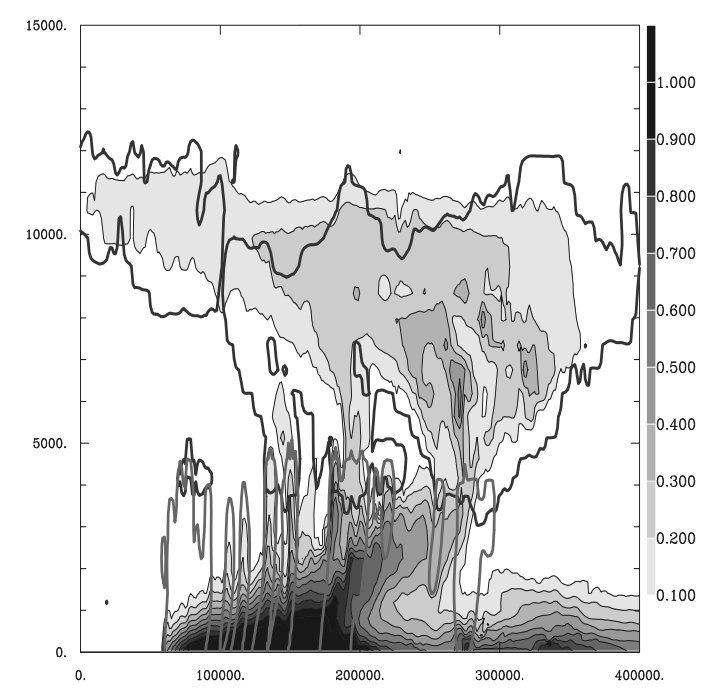

b)

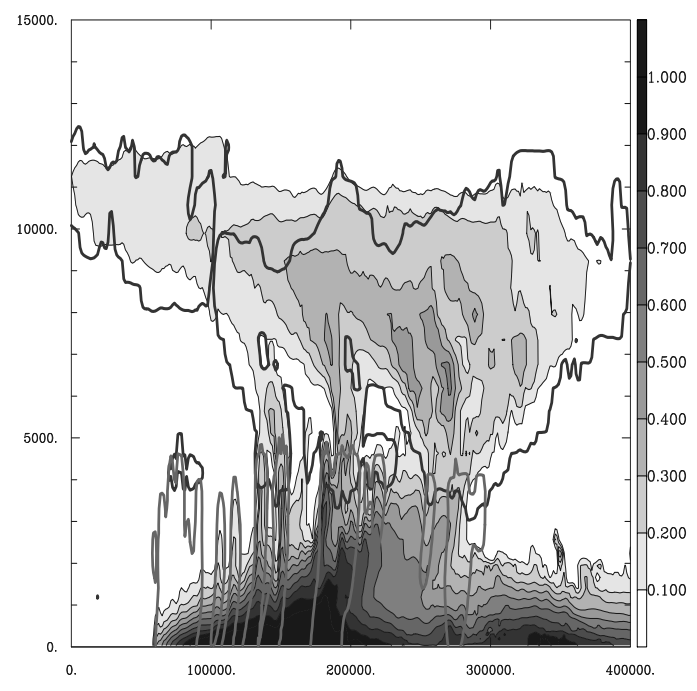

d)

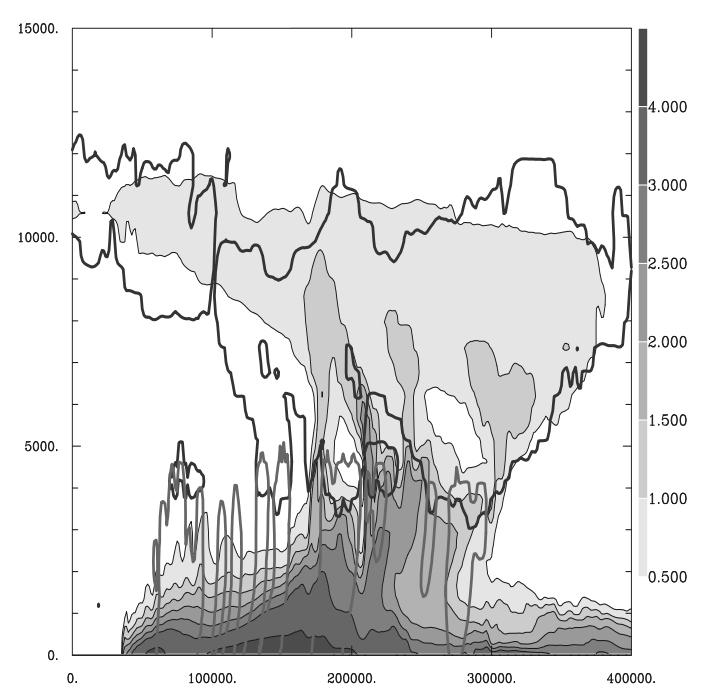

Figure 5: Concentration of the net scavenged coarse mode particles $\left[\mathrm{cm}^{-3}\right]$ deduced from the "COPT" simulation difference $\left(\mathrm{SCAV}_{0}-\mathrm{SCAV}_{1}\right)$ after 9 hours and for 3 initial dust layers: a) $[0-2] \mathrm{km}, \mathrm{b})[2-4] \mathrm{km}$ and c) [4-6] km, and d) the residency time [hr]. The glaciated part of the squall line is depicted by a black solid line, the grey line shows the rainshaft contours for $10^{-5} \mathrm{~kg} / \mathrm{kg}$. The "x" and "z"-axes are labeled in meters. 


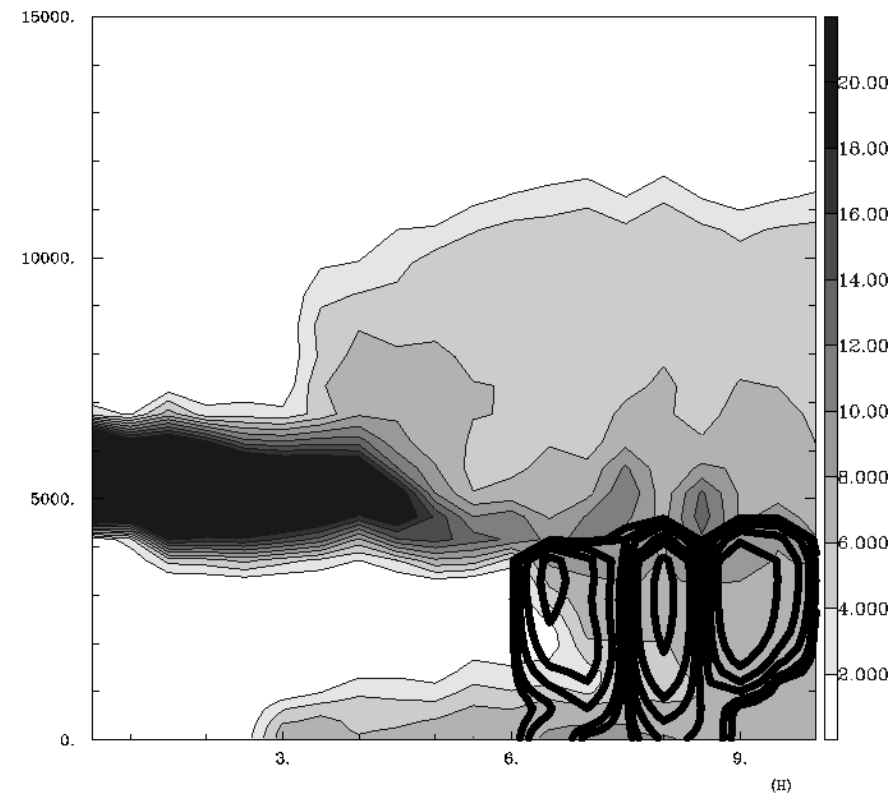

Figure 6: Time evolution of vertical profiles taken at $\mathrm{x}=225 \mathrm{~km}$. The coarse mode particles $\left[\mathrm{cm}^{-3}\right]$ in the $[4-6] \mathrm{km}$ layer case are displayed with the rain mixing ratio with solid contours superimposed in log scale from $10^{-5}$ to $10^{-3} \mathrm{~kg} / \mathrm{kg}$. 
a)

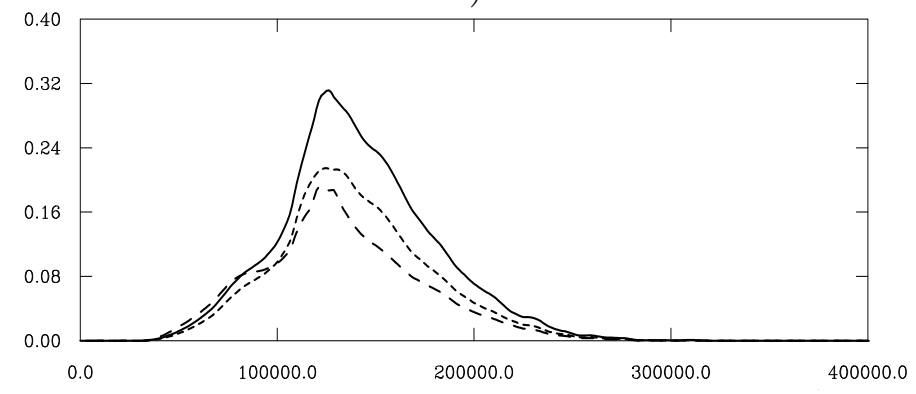

b)

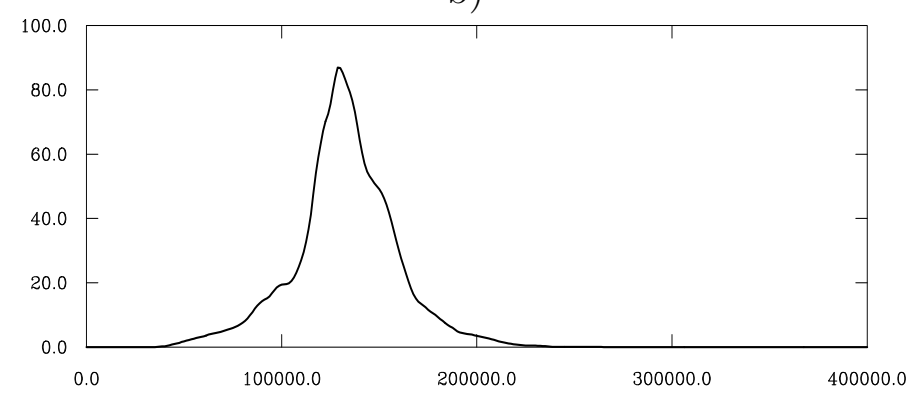

Figure 7: (a) Cumulated mass of scavenged AP by BCS $\left[\mathrm{kg} \cdot \mathrm{m}^{-2}\right]$ for the [4-6] km layer (dotted line), the [2-4] km layer (solid line) and the [0-2] km layer (dashed line), (b) cumulated precipitation $\left[\mathrm{mm} \cdot \mathrm{hr}^{-1}\right]$. The curves are obtained at ground level and after 9 hours of the "COPT" simulation. 